Int. J. Electrochem. Sci., 12 (2017) $1561-1571$

International Journal of

ELECTROCHEMICAL

SCIENCE

www.electrochemsci.org

\title{
Effect of Deposition Potential on the Structure, Electrocatalytic Activity and Stability of Pt Films for Methanol Oxidation
}

\author{
Siti Norsafurah Ab Malek, Yusairie Mohd \\ Faculty of Applied Sciences, Universiti Teknologi MARA, 40450 Shah Alam, Selangor, Malaysia. \\ *E-mail: yusairie@salam.uitm.edu.my
}

doi: 10.20964/2017.02.77

Received: 19 October 2016 / Accepted: 22 November 2016 / Published: 30 December 2016

\begin{abstract}
The effect of deposition potential on the structure and electrocatalytic properties of Pt films electrodeposited on Ti was investigated. By controlling a constant deposition potential either at -0.15 $\mathrm{V},-0.20 \mathrm{~V},-0.25 \mathrm{~V}$ or $-0.30 \mathrm{~V}$, various shapes of Pt structures such as cauliflower-like, durian-like, needle-like and worm-like can be observed by FESEM. The face-centered cubic (fcc) structure of all the prepared Pt films was confirmed by XRD. The highest specific electrochemically active surface area (ECSA) was obtained for Pt films with durian-like shape prepared at $-0.2 \mathrm{~V}$ with $6.0 \mathrm{~m}^{2} \mathrm{~g}^{-1}$ which gave the best catalytic activity and stability for methanol oxidation in alkaline medium.
\end{abstract}

Keywords: Pt films, electrodeposition, methanol oxidation, electrocatalytic activity

\section{FULL TEXT}

(C) 2017 The Authors. Published by ESG (www.electrochemsci.org). This article is an open access article distributed under the terms and conditions of the Creative Commons Attribution license (http://creativecommons.org/licenses/by/4.0/). 